\title{
EL ENSAYO: DESDE LA INVENCIÓN A LA CRÍTICA EN ENRIQUe VILA-MATAS
}

\author{
Alfredo Aranda Silva \\ (University of Wisconsin-Eau Claire)
}

[...] da un tempo in qua, io non dico mai quello che io credo, né credo mai quel che io dico, et se pure $\mathrm{e}^{\prime}$ mi vien detto qualche volta il vero, io lo nascondo fra tante bugie, che è difficile a ritrovarlo (Maquiavelo, 2013: 270)

\section{.Niccolò Machiavelli. Lettera a Francesco Guicciardini (17/05/1521).}

The crisis will do me good physically like a sea bath [...] (Draper, 1978 :65). Friedrich Engels. Letter to Karl Marx (15/11/1857).

El universo de la experiencia ensayística en Enrique Vila-Matas se mueve entre la idea que afirma -al decir de Francisco Jarauta- que somos nuestras preguntas, el entendimiento de la verdad — tal y como le ocurría a Maquiavelo a la hora de separarla de la mentira- como coyuntura indistinguible de la ficción y el imperativo moral de llevar el concepto de crisis a un ámbito de metodología creativa y credo personal; actuando así la crisis en Vila-Matas con la misma bonanza que lo hacía en Engels: como un baño de mar. Descreído de la farmacopea de las respuestas ${ }^{1}$ y apoyado en un claro sentido de "estilo tardío" , a la vez que dando prioridad a una exigencia de búsqueda, experimentación e inconformismo, el ensayo de Vila-Matas apela casi por encima de todo al derecho a contradecirse y seguir adelante aunque no entendamos nada. Estamos así ante un tipo de ensayo que apunta, en efecto, a un recurrente horizonte de mutación y atolladero, que

\footnotetext{
Recordemos que "La réponse est le malheur de la question" (Blanchot, 1969: 15).

2 On Late Style (Pantheon Books, New York, 2006) -obra que vino a continuar y profundizar el artículo "Thoughts on Late Style" (London Review of Books, Vol. 26, No. 15, August 5, 2004)- fue un estudio en el que Edward Said estuvo trabajando durante los últimos meses de su vida. Su título e inspiración provienen del ensayo de Adorno "Spätstil Beethovens" (Moments musicaux, 1964), escrito en su mayor parte durante 1937. Said estudia el estilo tardío para dar cuenta de las obras y temperamentos que informan sobre una desentonación crucial en el arte, buscando el artista una lectura final de sí mismo en sedición contra los presuntos, aparentemente intocables, ciclos de la experiencia y la sazón humanas; esto es, los artistas de estilo tardío convierten "lo tardío o extemporáneo, y la madurez vulnerable, en una plataforma para la alternativa y los modos no reglamentados de subjetividad, al mismo tiempo que todos [...] tienen tras de sí una vida entera de preparación y esfuerzo. [...] se enfrentan a los grandes códigos totalizadores de la difusión cultural y la cultura occidental del siglo XX. [...] Es como si, tras alcanzar cierta edad, rechazaran su supuesta serenidad o madurez y su afabilidad o congraciamiento oficial. Sin embargo, ninguno de ellos niega o elude la mortalidad, sino que esta regresa una y otra vez como tema que socava y eleva de un modo extraño sus usos del lenguaje y la estética." (Said, 2009: 156).
} 
hace crítica de la crisis y viceversa, que conforma un testimonio cultural de nuestro tiempo de signo europeizante-modernista y que entrega, en última instancia, una escritura que no es sino una interiorización vinculante del ejercicio creativo para tratar de argamasar, hasta sus últimas consecuencias, simiente ensayística y ficción narrativa.

Aunque no se les ha prestado normalmente la importancia que podrían merecer, sus entrevistas inventadas, así como su etapa de formación periodística en general ${ }^{3}$, representan para su autor no solo la puerta de entrada al brío publicador y la sociedad cultural de la Barcelona tardofranquista, sino la primera razón de ser de aquello en lo que devendrá su futuro ensayo. Si por algún lugar empieza Vila-Matas a ser sus preguntas es a través de una ocupación periodística que el autor se toma literalmente como el taller de escritura del ensayista narrativo e inventivo que está llamado a ser.

Téngase en cuenta que, si bien los hubo, los relativos precedentes en aquella España de finales de los años sesenta tampoco eran legión. Si nos fijamos en los trabajos críticos del grupo del 27 y los componentes de la generación del Novecientos encontramos, por ejemplo: en los diarios de Juan Larrea entre el dietario y el ensayo -con relación, en especial, al Dietario voluble (2008) de Vila-Matas-, el absurdo y la ironía en el ensayo brevísimo de Julio Camba ${ }^{4}$ o la técnica empleada, e incluso ciertas temáticas abordadas, en los paradigmáticos ensayos novelados de Eugeni d'Ors La ben plantada (1911) y Oceanografia del Tedi (1918) (no traducidos al castellano sino a principios de los años ochenta) algunas de las obras y elementos literarios parangonables a Vila-Matas. Hay, igualmente, otras formas literarias de esta época y alrededores que no son ajenas a parte de lo que hará más tarde en la combinación de literatura y periodismo que se da en las dos novelas memorialistas de Cansinos Assens $\mathbf{s}^{5} \mathrm{o}$ en los "autorretratos indirectos" entre la novela y el ensayo de Manuel Azaña que ha señalado José-Carlos Mainer ${ }^{6}$.

Es muy probable que, por lo demás, el antecedente más claro de escritor español adherible a Vila-Matas durante la primera mitad del siglo XX no sea otro que Ramón Gómez

\footnotetext{
Primero, desde mediados de 1968, con artículos de crítica cinematográfica -así como reportajes, semblanzas y entrevistas del mundo del cine en general- y ya a partir de 1982 con artículos, crónicas y ensayos literarios.

4 A ello se han referido Jordi Gracia y Domingo Ródenas de Moya en relación a los artículos de Camba, textos de "una perspectiva insólita, la del humorista que observa escéptico la realidad y la retrata con una sorna translúcida a cuyo través se recorta la silueta de la crítica o la denuncia. [...] Camba no se limita a registrar lo que sucede y reflexionar sobre ello sino que, mediante la ironía (a veces por el camino de la reducción al absurdo), combina constatación y reflexión, siendo esta por lo común implícita y por tanto inferible." (Gracia y Ródenas de Moya, 2008: 41-42).

5 Procedentes de los diarios del autor y publicadas póstumamente bajo los títulos La novela de un literato (1982-1995) y Bohemia (2002).

6 Véase Mainer, "Para una epopeya del ensayista: Manuel Azaña como ejemplo”, en Gracia y Ródenas de Moya (eds.), 2015: 94-99.
} 
de la Serna ${ }^{7}$. Sin que aparezcan concomitancias o alusiones recurrentes entre ambos -apenas encontramos siquiera aisladas o explícitas referencias deudoras hacia el autor madrileño en la obra vila-matiana-, sin embargo, el carácter vanguardista y transgresor de Gómez de la Serna, su filoparisinia y exilio voluntario, su vocación multidisciplinar y regular colaboración en prensa -incluso el carácter entre surrealista e histriónico-lúdico que muestra Ramón en ciertas fotografías- y, especialmente, esas biografías que escribió sobre Valle-Inclán, Azorín o sí mismo (en las que el personaje reseñado suponía esencialmente un subterfugio para la extraversión, la divagación y la acumulación de un anecdotario tan verdadero como inventado), sitúan un claro tendido temperamental entre ambos autores; haciendo, en todo caso, de los mundos ramoniano y vila-matiano un par de espacios marginal o discontinuamente conectados.

Si con el fin de asomarnos cronológica y panorámicamente a la evolución del ensayismo de Vila-Matas prestamos atención a los comienzos, a un punto intermedio y al presente del autor observaremos una manifiesta relación entre las partes. Es relativamente conocido que todo comienza con la revista Fotogramas y a partir de una propuesta de colaboración profesional que Vila-Matas recibe por parte de Elisenda Nadal, mientras el futuro escritor paseaba un día del verano de 1968 por las galerías comerciales de Platja d'Aro ${ }^{8}$. Son años fundamentales porque en ellos Vila-Matas -que entonces quiere ser realizador de cine- experimentará en carne propia, y por primera vez, la incumbencia pública de escribir y la implicación retroactiva de ser leído; localizándose en este momento el embrión de su futuro ensayo: decidiéndose a querer ser escritor no encontrará mejor manera de lograrlo que explicándoselo a sí mismo desde las dudas, indagaciones y osadías que aparecen en sus escritos.

Lo que hace, pues, poseedor de un timbre distintivo a su ensayismo será, por este orden, un precoz sedimento inventivo formalizado a través de la entrevista cultural, una especificación de articulismo literario -multidisciplinar, ensamblado por igual en la imaginación desinhibida y la disquisición crítica- que desde sus comienzos se muestra más claro y compacto que la novelística del autor ${ }^{9}$ y, por último, una extroversión que hace virtud de la necesidad desde la

\footnotetext{
7 Así lo ha entendido Jordi Gracia, que cifra entre los escritores españoles de la primera mitad del siglo XX a Gómez de la Serna como el único "avatar retroactivo de Vila-Matas" (Gracia, "Todo mentira", El País, 27/11/2015).

8 La periodización de las colaboraciones de Vila-Matas en Fotogramas cubrirá dos años de forma continuada, concretamente entre los meses de agosto de 1968 y 1970. Más tarde habrá alguna colaboración más por motivos excepcionales. Fue el caso, v. gr., del artículo "Solo se debuta una vez" (Fotogramas, 15/11/1986) o, veinte años después, del texto "Cuatro flashes sobre Fotogramas" (Fotogramas \& DVD, número extra 2, 2006).

9 No le falta razón a Pozuelo Yvancos, por tanto, cuando señala que ya en la primera recopilación de artículos de VilaMatas -El viajero más lento (1992), con textos que van desde finales de los años sesenta hasta principios de los noventaencontramos al Vila-Matas articulista y ensayista de hoy: "En su obra ensayística Vila-Matas se ha mantenido fiel desde los inicios a las determinaciones principales de su forma y estilo. Quiero decir que el articulista Vila-Matas de principios de los ochenta, se parece más al del año 2006, que el novelista de entonces al de ahora." (Pozuelo Yvancos, 2010: 155).
} 
naturaleza "inmadura", de estilo tardío, que tiene lugar en su última y presente etapa productiva. Nos referimos con ello, como apuntábamos anteriormente, a una "inmadurez" basada en la perentoriedad por empujar los límites, por desdecirse, cuestionarse y vincularse a cierta arritmia formal que repare más en la pesquisa que en la armonía. Con ello, en pocas palabras, su ensayismo ha terminado por hacer crítica literaria desde la ficción. En su propia opinión, si en un primer momento su obra se dedica a narrar y en una segunda época ofrece el inopinado comentario metaliterario sobre su propia narración, hoy aquélla se encuentra en la coyuntura de tratar de hacerse con un tipo concreto de genuina verdad ${ }^{10}$; entendida esta como exploración del abismo a través de la ficción y tan desfigurada de certidumbres como legítimamente ambiciosa.

Antes de nada hay que recordar que, en Fotogramas, tendrá dos debuts: el que supondrá la primera aparición de su nombre ${ }^{11}$ a través del artículo: "Clint Eastwood o el mito de un rostro impasible" (Fotogramas, 23/08/1968) y el debut formalizado a través de una entrevista inventada y firmada por Mary Holmes bajo el título: "Marlon Brando: 'Sé que puedo terminar asesinado como los Kennedy o Luther King'" (Fotogramas, 05/07/1968) ${ }^{12}$. Cuando en su momento tratamos de averiguar quién fue Mary Holmes, supuesta periodista de Variety ${ }^{13}$, no dimos con ninguna pista fiable o noticia segura. No es descabellado pensar que el nombre de Mary Holmes fuera ficticio o utilizado discrecionalmente por la redacción de Fotogramas según se necesitase del mismo. Recuérdese que se le ofrece la traducción de la entrevista a Brando por una necesidad puntual, ya que la responsable habitual de tal cometido en Fotogramas, Olga Spiegel, estaba de vacaciones en aquel mes de agosto de 1968. Lo cierto es que Fotogramas publica entrevistas firmadas por Mary Holmes (en títulos que, en ocasiones, no tuvieron desperdicio y que sumaron un total de 25, incluida su entrevista inventada) desde enero de 1968 hasta marzo de 1975 y que, con la excepción de dicha falsa entrevista a Brando, Vila-Matas nada tuvo que ver con ellas. Cabe añadir que, con posterioridad, ha dado por hecho que la entrevista de marras habría corrido

\footnotetext{
10 Por mucho que lo apócrifo, lo inexistente y lo fingido hayan formado parte ineludible de los procesos de sondeo de la escritura de Vila-Matas, no resulta extraño, máxime conociendo la naturaleza refutadora del autor, que en un momento como el actual, en el que un término tan cacareado como el de "posverdad" se ha encaramado al podio de las palabras más utilizadas por los medios comunicación y las revistas científicas en 2016, el autor esté buscando hoy en su obra la absoluta contracara de lo fraudulento.

11 Entonces sin guion, que, como se sabe, será posteriormente introducido entre sus dos apellidos, Vila y Matas.

12 Titulado más tarde, tanto en El viajero más lento (Anagrama, 1992) como en su reedición El viajero más lento. El arte de no terminar nada (Seix Barral, 2011), "El rostro impasible".

${ }^{13}$ Semanario creado en Nueva York en 1905 por Sime Silverman y al que, al parecer, y siempre según Vila-Matas, 
a cargo de Julie Gilmore ${ }^{14}$. Sin embargo, Holmes o Gilmore no son los únicos nombres de las supuestas periodistas que habrían estado detrás de esta ya famosa entrevista. En un encuentro con jóvenes, por ejemplo, dentro del marco de la Feria Internacional del Libro de Guadalajara (2015), Vila-Matas afirmó que la autora de la entrevista fue Kay Kendall, quizá inspirado por la conocida actriz inglesa del mismo nombre.

Retomando los dos textos mencionados de Fotogramas podríamos decir, pues, que la crítica de cine publicada en agosto cabría considerarla como su debut oficial como articulista -al ir aquella firmada por él- y la entrevista ficticia a Brando, publicada un mes antes bajo el nombre de Mary Holmes, habría sido paradójicamente su segundo u oficioso debut. El artículo del debut oficial (mecanografiado en la máquina de escribir de su abuelo, en la casa de éste de la calle Enric Granados de Barcelona) incluía cuatro fotografías de Clint Eastwood y se centraba en la exploración de Sergio Leone sobre el mito del western norteamericano integrado en el cine; lo que el realizador romano llevó a cabo -venía a decir en su artículo- a través, tanto de un peculiar desarrollo de la picaresca latina, como de cierta construcción de una contramitología moral, que acabaría dando con un invento de amplia explotación comercial. Leyendo el artículo, difícilmente podríamos pensar que su autor es un joven de 20 años, que no ha estudiado más que algunas asignaturas universitarias de Derecho y posteriormente de Periodismo, sin experiencia ni conocimientos especiales de ningún medio de comunicación ni de círculo literario alguno, así como tampoco provisto, siquiera, de un zurrón de lecturas autodidactas más o menos importantes que pudiera cubrirle las espaldas. A pesar de lo cual el artículo, sin ser exactamente ni extenso ni profundo, transita con soltura, subjetividad y seguridad, por cuanto dice: presenta la personalidad y la evolución de Eastwood, introduce el cine e inquietudes de Leone, establece la conexión entre ambos y fija una solvente interpretación crítica que denota un aparente dominio del oficio.

Esto es, desde sus primeras colaboraciones en Fotogramas sabe encontrarse cómodo, o así lo parece, en una escritura hecha de crítica y tendente al bosquejo interpretativo. Pero, además, la temática y el resultado final de sus escritos formalizados a través de entrevistas, notas críticas o artículos, condensan una serie de parámetros ampliamente alineados con los futuros intereses poéticos del autor; aquellos que, arborizados en torno a lo ensayístico y lo narrativo, conocemos hoy. Por citar brevísimamente unos pocos casos cabría fijarse, por ejemplo, en sus

\footnotetext{
14 Como tal lo aseguraría Vila-Matas, v. gr., tanto en "Lo que Brando decía" (Dezine, 01/10/1980) como en el texto "Entrevista para Australia" (cfr., http://www.enriquevilamatas.com/escritores/escrwillwilkinson2.html), publicado en inglés en la página web oficial del autor con, cuando menos, varios datos inexactos -ya que Vila-Matas ingresa en Fotogramas no en agosto de 1967 sino de 1968 y respecto a sus entrevistas falsas publicadas nos consta que no hubo 
entrevistas (esta vez reales) a: Azcona ${ }^{15}$ (con contenido sobre las relaciones entre el cine y la literatura), Jorge $\mathrm{Grau}^{16}$ (el cual se extiende sobre el componente reflexivo y no narrativo del arte), Raimon $^{17}$ (con el que conversa acerca de la clandestinidad y la posibilidad de trabajar dando la espalda a las estructuras comerciales), Jaime Camino ${ }^{18}$ (entrevista en la que, cuando le pregunta sobre el experimento que supone cada nuevo film suyo en busca de nuevas fórmulas narrativas, responde que lo que más podría molestarle es que sus películas se parecieran todas las unas a las otras) o Carlos Estrada ${ }^{19}$ (el cual discurre sobre la necesidad del creador para evadirse en los personajes). Respuestas y contenidos, en fin, que vienen de preguntas que hace con un sentido concreto para el autor que está por llegar, tratándose, al cabo, de una serie de antiguos trabajos de Vila-Matas que testimonian hoy cómo su labor periodística no pareció nunca caer en saco roto, en relación a sus entonces próximos horizontes de composición y convicción literarias ${ }^{20}$.

Además de estas entrevistas, entrega también para Fotogramas: crónicas, notas de cine, estampas y reportajes que lindan claramente con lo ensayístico (un buen ejemplo de todo ello sería, por ejemplo, “¿Adónde va el cine mesetario?" [Fotogramas, 14/02/1969]) a la vez que se ocupa de los más diversos temas, desde el cine de la Escuela de Barcelona, hasta la historia cinematográfica española, pasando por el análisis del nuevo cine alemán, sueco, italiano, canadiense, holandés y yugoslavo — entre otros— o por la salud y las ideas del teatro español de finales de los años sesenta. Conforme a su vocación cinematográfica, llega a interesarse incluso por el trabajo técnico de los operadores-jefe en el cine a través de, por ejemplo, entrevistas

\footnotetext{
15 Cfr., Vila-Matas, "Azcona, el guionista número 1 del cine español" (Fotogramas, 13/09/1968). Años después VilaMatas dedicaría otro texto a Azcona con "La verdadera historia del guionista Azcona" (Bocaccio73, Julio 1973).

16 "V-M - ¿Qué pretende hacer en «La cena», su nuevo film? / J. G. - «La cena» es una no-historia. Es decir: solo cuento un momento muy breve en la vida de unos personajes. Es un momento tan breve que dura solo el tiempo de beberse una copa. Intento explicar la gran complejidad e intensidad de un solo momento, a través de las sugerencias, reflexiones y recuerdos que este ofrece. En cierto modo, «La cena» está en la línea de «Acteón». Es un film muy poco Ilano. Es más bien intrincado, difícil." (Vila-Matas, "El director que dijo No a Sara Montiel" [entrevista a Jorge Grau], Fotogramas, 27/09/1968). Poco después Vila-Matas incluirá en su segundo cortometraje -rodado en Port Lligat con dinero prestado por su padre bajo el título Fin de verano (1970)- una escena que recuerda, salvo en que está rodada a la luz del día, a la cena referida por Jorge Grau.

17 Cfr., Vila-Matas, "Raimon: 'Siento que me van eliminando'" (Fotogramas, 08/08/1969).

18 Cfr., Vila-Matas, "Jaime Camino: 'Prefiero ganar un premio en Venecia o Cannes que aspirar al Oscar'” (Fotogramas, 24/01/1969).

19 "[...] lo más importante es trabajar. Me siento muy feliz entonces. Además, no me gusto nada a mí mismo y prefiero meterme en otro personaje. Es una especie de evasión continua" (Vila-Matas, "Carlos Estrada: 'No me gusto nada'", Fotogramas, 13/12/1968).

20 Incluso algún futuro título del autor -como es el caso de París no se acaba nunca (2003)- procede de esta época: "Quedan aún muchas cosas vistas y vividas por contar. [...] pero este artículo no acabaría nunca, del mismo modo que París tampoco se acaba nunca, sobre todo este París que he encontrado con lucecitas navideñas engañosas y fiesta continua." (Vila-Matas, "París ¿adónde fue tu revolución?", Fotogramas, 17/01/1969).
} 
grupales. En otras ocasiones, por último, cubre los principales festivales de cine europeos de la época ${ }^{21}$ o diagnostica una concreta tipología cinematográfica en el espacio de un año ${ }^{22}$.

Hay también espacio en esta época para que las introducciones o los cierres de sus entrevistas se tiñan de espontáneas intenciones descriptivo-literarias y de anécdotas personales con las que el entrevistador logra interactuar, coloquial o seductoramente, con su entrevistado; instalándose así en lugares y tonos poco comunes en relación al recorrido que media entre una sesión de entrevista formal y el resultado escrito de la misma ${ }^{23}$. Encontramos también en Fotogramas, aunque son todavía los menos, textos que son ya, directamente, de un articulista que madura sus opiniones a través de una conciencia y un dominio abiertamente ensayísticos. Así se observa, por ejemplo, cuando decortica el cine de Rohmer — con ironía culturalista y atento análisis crítico-a través del artículo "Ma nuit chez Maud, diálogos católico-marxistas en un salón burgués" (Fotogramas, 07/11/1969). Aparece igualmente, por último, el articulista literario propiamente narrativo: así lo observamos, verbigracia, en "La larga agonía de los actores fuera del agua" (Fotogramas, 01/08/1969), ejercicio de crónica mundana de la cultura contemporánea, al que incorpora un estilo personal y desenfadado a la vez que agudo; dando sarcástica y expositiva cuenta de docenas de personajes del cine, la literatura, el teatro, la prensa o la pintura, en abigarrada conexión con presuntos comentarios de los mismos: sus vestimentas, sus trabajos recientes o la presunción de sus sentimientos.

Si con el fin de abordar someramente el apartado de las entrevistas falsas del autor retomamos el que fuera el citado debut oficioso de Vila-Matas en Fotogramas, aquel que -recordémoslo- tuvo lugar con el texto "Marlon Brando: 'Sé que puedo terminar asesinado como los Kennedy o Luther King'" (Fotogramas, 05/07/1968). Encontramos aquí a un Brando a contracorriente, entre surrealista y extravagante, vistosamente situado en la modernidad de una revista en la que Vila-Matas se abre paso con aparente naturalidad desde el arbitrio de

$21 \quad$ Algo que ocurre también en la segunda etapa de Vila-Matas como crítico y corresponsal de cine ya fuera de Fotogramas; así, por ejemplo, el artículo "Cannes 77: Bajo el signo de los Taviani" (Destino, 02/06/1977).

22 Puede seguirse todo lo dicho, entre otros, en los siguientes artículos: “iHa muerto la Escuela de Barcelona? (Fotogramas, 07/02/1969) -reportaje que tendría su continuación en el articulismo de Vila-Matas 30 años más tarde con "Una evocación de la Escuela de Barcelona" (La Vanguardia, 26/02/1999)-, "No hacía falta morir por esto' o el 'boom' del cine canadiense" (Fotogramas, 17/01/1969), "Yugoslavia: visión de un cine joven" (Fotogramas, 13/09/1968), "Dos realizadores holandeses: Pim de la Parra y Wim Verstappen" (Fotogramas, 12/12/1969), "Roland Klick o la nueva Alemania" (Fotogramas, 10/01/1969), "San Sebastián 70. Una película de 10 días con muchas 'vedettes'" (Fotogramas, 24/07/1970), "El operador-jefe" (Fotogramas, 30/01/1970), "El cine a la hora sueca" (Fotogramas, 29/11/1968), "Bertolucci, después de la revolución" (Fotogramas, 16/01/1970), "Almería, cine independiente A-Z, de Fausto Romero" (Fotogramas, 19/12/1969) o "¿Adónde va el cine mesetario?" (Fotogramas, 14/02/1969).

23 Unos pocos botones de muestra al respecto podrían ser: "Al servicio de su majestad James Bond" (Fotogramas, 16/05/1969), "El cine lo es todo para mí, no sé hacer otra cosa'" [entrevista a Sonia Bruno] (Fotogramas, 11/10/1968), "Marisa Paredes: 'Soy actriz por llevarle la contraria a la vida'" (Fotogramas, 11/04/1969) o "Elena María Tejeiro, una 'gata' en el cine español" (Fotogramas, 21/02/1969). 
la improvisación, la mascarada y el desparpajo —características que, no por azar, definirán parcialmente su posterior ensayo. Junto a ello, hay elementos de reflexión intrínseca sobre el mundo y sobre el propio Brando, solidarios de una pretensión por contarse y de explicarse a uno mismo. Estamos, por ende, ante una entrevista que merecería figurar en los anales del periodismo español de ficción, por cuanto de invitación a la estupefacción tiene su lectura: apenas comenzada la entrevista, se refiere a Brando como "apóstol de la paz"; Ilamando acto seguido la atención en torno al actor estadounidense como un hombre que habría querido romper con toda su vida anterior — con los veinte años de exitosa carrera cinematográfica que entonces tenía a sus espaldas-, para dedicar su existencia a contrarrestar, desde el icono de influencia mediática que representa su figura, la atmósfera de conflictos bélicos, desigualdades sociales y discriminaciones raciales que asolaban entonces el mundo —como todavía ocurre desgraciadamente en nuestros días.

Para reafirmar su impostura, se ha hecho estratégicamente eco durante la introducción de la entrevista del componente de extravagancia y locura que muchos parecían observar entonces en el progresivo despertar mesiánico-social de Brando, el cual afirma "buscar adictos" para su propósito y empresa, consistente en despertar tantas conciencias, perniciosamente dormidas entre la popularidad y la fortuna, como le fuera posible. No deja de ser llamativamente coherente, por cierto, que buena parte de su labor ensayística se haya edificado a través de un reiterado intento por despertar conciencias -tanto escritoras como lectoras- en torno a la perversión artística manifestada. En su opinión, por el acomodamiento de ciertos autores adeptos a las fórmulas del éxito comercial y el realismo ramplón; gozantes, por tanto, de la popularidad y fortuna que estaría criticando el Brando vila-matiano.

En suma, leyendo la entrevista, se aprecia que Brando quiere limpiar su conciencia y prepararse para el día que le "toque reventar", a lo que añade que sus actos y opiniones no obedecen a ninguna mezquina treta publicitaria ya que, si quisiera, podría dejarse morir: "bajo el peso de una montaña de dólares". Tras admitir que su pensamiento le lleva a sentirse amenazado, en la medida en la que lo estuvieron Luther King o los hermanos Kennedy -de aquí saldrá el título del texto-, y que se siente atraído por las mujeres exóticas, poéticas y distintas a las "mujeres en serie" que produce la civilización occidental, Brando/Vila-Matas se expresa del 
siguiente modo en respuesta a la pregunta de si no le importa interrumpir su brillante carrera de veinte años en el cine:

\begin{abstract}
Claro que me importa. Pero en la vida, en un momento determinado, hace falta elegir. [...] si te planteas la alternativa de elegir, debes Ilegar hasta el fondo. Si el problema no te atañe, mejor para ti. Nadie te impide hacer caso omiso. Pero a mí el problema me afecta profundamente. $Y$ he tenido que actuar. Otras veces no he tenido el valor de hacer mi propia elección. Pero si también en esta ocasión me hubiera comportado como un bellaco, hubiera dejado de existir a mis propios ojos. [...] Veinte años tachados, borrados. Me pesaban, físicamente, mentalmente, espiritualmente. Veinte años que han "engordado" todas mis células negativas, mis pensamientos y mis sensaciones más banales y falsas. Veinte años quemados en el altar de la vanidad, de la felicidad personal. Cosas que no cuentan (Mary Holmes [Vila-Matas], "Marlon Brando: 'Sé que puedo terminar asesinado como los Kennedy o Luther King'", 05/07/1968: 8).
\end{abstract}

Sea o no premeditado, el grueso de la entrevista discurre a través de un lenguaje entre coloquial, grotesco y sañudo, con un Brando maniático y suspicaz; determinado a sacudir conciencias en el seno de su profesión a la vez que a cambiar de vida de una forma irrevocable - en su caso, a alejarse de la superficialidad de los días regalados y de la inconsciencia de los males ajenos. El caso es que podía haber optado por inventar a un Brando risueño o no problematizado, pero lo que hace es, desde la primera oportunidad que tiene de ficcionalizar: situar a su personaje en un hábitat de crisis (tan benigno en general para su escritura, recordémoslo, como un baño de mar pleno de efectos terapéuticos o renovadores) que le permite, además, senderear por el ensayo. Por otra parte, el traslado de los hechos descritos en la entrevista a una concepción de paralelismos históricos, en relación al entonces futuro literario de Vila-Matas, no resulta extraño si tenemos en cuenta, entre otros, el tema que caracterizará a ciertos personajes escritores o narradores vila-matianos, que buscarán cambiar de vida: bien a través del abandono de la escritura (abriéndose al horizonte ideológico de la perspectiva bartlebyana), bien a causa de un "pasaventiano" deseo de desaparición. Todo lo cual muestra en Vila-Matas una paleta de colores que va desde la vertiente extrema de "mandarlo todo al diablo"24, hasta la discreta

\footnotetext{
$24 \quad$ Es esta una expresión que, aunque ya se había apuntado previamente en la obra de Vila-Matas, aparece plenamente abordada en el relato "Mandando todo al diablo" (Hijos sin hijos, 1993) para volver a emerger después con cierta regularidad. Diversas modulaciones de personajes como el Wakefield del cuento homónimo de Hawthorne (publicado en New England Magazine en mayo de 1835) o el Flitcraft de Hammett en Maltese Falcon (1930), entre otros, resuenan intensamente tras ella. 
actitud de la retirada, conforme a la ristra de personajes grises y anónimos que pueblan toda una estética de la historia literaria a la que será especialmente sensible su narrativa ${ }^{25}$.

Igualmente, cuando más adelante Brando desgrane en la entrevista sus opiniones sobre temas como la locura, el pasado, la felicidad, el futuro o el lenguaje se estará pronunciando el actor estadounidense a través de la máscara deVila-Matas en torno al tipo de elecciones humanas que diversifican y deciden los caminos de cada individuo, en función del grado de compromiso personal que vibra en su interior. A la manera del narrador de Céline al comienzo de Voyage au bout de la nuit (1932) y discurriendo sobre el error, el binomio Brando/Vila-Matas enuncia que: una vez decidamos algo, debemos ir hasta el final. Añade así, sintomáticamente a través de su falso Brando o viceversa, que la falta de valor para elegir ha podido llevarle ocasionalmente a actuar. Pero el juego de espejos o mecanismo de refracciones contrapuestas no termina aquí; así ocurre, en especial, cuando observamos que logra situar a "su personaje" precisamente al final del camino que a él le queda todavía por recorrer. Imagina de esta forma cómo sería una posible ubicación en la dilatada proyección del éxito, esto es, experimentando por sí mismo dentro de un primer nivel de máscaras - el mismo ennui o cansancio literario que a él aún no le ha sido dado conocer, pero sobre el que se siente intrigado desde que conociera pocos años atrás al escritor Pontano, que debe acudir a la promoción de su última obra literaria en La notte (1961) de Antonioni. Una última opinión de interés en Brando/Vila-Matas se extiende, como decíamos, hacia una explícita apología del futuro, bajo la que puede leerse tanto un rechazo de la inmediatez sociocultural española, como una indudable desconfianza por la palabra (extremo, por otra parte, tan visitado en la obra de Vila-Matas a través de Beckett, Céline, Musil o Kafka, entre otros):

[...] Toda la gente con un poco de personalidad, de inteligencia y de dignidad, tiene que ser [...] un poco loca. [...] Lucharé por las cosas en las que creo profundamente. Luchar con fuerza. Hasta que reviente. [...] Mi felicidad en el presente está a millones de años luz de distancia. Pero esto no me preocupa. [...] No me gustan las miradas atrás, el pensamiento del pasado me aburre. Pensar en el futuro es lo único que me despierta. [...] Las palabras son una institución muy absurda. A menudo irritante (Mary Holmes [Vila-Matas], op. cit., 8). 
En suma, con su entrevista inventada a Brando, anuncia ya ciertos y fundamentales filamentos temáticos, así como diversos parajes de su conciencia personal, que se verán desarrollados y potenciados en su futuro como autor contrastado, ya sea en sus novelas o ensayos. Recordemos, por ejemplo, que en relación al párrafo que acabamos de citar, más tarde habrá varios relatos basados en una experiencia personal del autor, cumpliendo parte de su servicio militar en un pabellón psiquiátrico, a causa de un episodio que había comenzado con una ingesta de distintas drogas y un posterior ejercicio simulador de la locura. O que también luchará en sus ensayos y novelas por aquello en lo que cree poéticamente "hasta reventar", así como por anteponer una mirada puesta hacia el futuro en detrimento de un pasado que dice aburrirle y que por ello, precisamente, será modificado en sus libros; recomponiendo así un particular canon literario relativamente al margen de los grandes nombres. No cabe duda, pues, de que con esta entrevista falsa iba al encuentro de un destino de resortes, creativamente empujados desde sus propias circunstancias ideológico-históricas; a la vez que, como autor en la sombra, estaría situando subliminalmente el texto inventado en la perspectiva de su futura relación con nuevos lectores. Como las cartas contestadas por Satie sin haberlas abierto, Vila-Matas se contesta las preguntas de entrevistas inexistentes ${ }^{26}$, estableciendo los ábsides del interés artístico no tanto en lo que se dice, sino en el modo de hacerlo. A su manera discreta y excéntrica, aporta de este modo su contribución personal al engrose de las actitudes que inquietaron y renovaron los límites entre lo periodístico y lo literario; actuando el ensayismo inventivo que opera en sus artículos como una suerte de reflexión ensimismada en torno a los más diversos motivos literarios. Apreciamos, de hecho, detrás de esta invención de cariz reflexivo, una apuesta por saltarse reglas, por apuntalar un mundo propio y comprometerse con las nacientes ideas sobre su escritura.

Todo ello conocerá, todavía, un nuevo eslabón con "Lo que Brando decía" (Dezine, 01/10/1980), entrevista de la que ya nos hicimos eco antes y que no supone sino una nueva muesca -quizá habría que decir más bien mueca- de su invención periodística en torno a la figura de Brando, pero ejercida, para esta ocasión, desde un nivel más claro de buscada complicidad con el lector. Han pasado 12 años y en 1980 Vila-Matas ha ganado en seguridad y madurez, encontrándose en condiciones de continuar aquel primer vínculo con Brando publicado en Fotogramas, a través de un trabajo mejor injertado en su propia evolución como escritor 
y desplegando un tono de ficción narrativa palpablemente desenvuelto. Estas dos entrevistas falsas y las relaciones que mantienen entre ellas podrían, de hecho, simbolizar ampliamente los orígenes y las razones evolutivas del escritor de ensayo que inventa y que es Vila-Matas. Si nos fijamos así — siquiera sucintamente - en el contenido de la nueva falsedad sobre Brando, nos apercibiremos de la audaz mezcla de ficción y realidad que contiene. Para empezar, la entradilla de la entrevista (no sabemos si escrita por él mismo o por algún redactor de Dezine a instancias del escritor):

\begin{abstract}
Se cumplen diez años [sic] del día en que, firmadas por Julie Gilmore, aparecían en las páginas de Fotogramas estas declaraciones de Marlon Brando. En realidad, la entrevista fue totalmente inventada por E. Vila-Matas que, como redactor de la revista, había recibido el encargo de traducir del inglés ciertas declaraciones de Brando a la Gilmore. Al parecer, Vila-Matas no sabía una palabra de inglés y optó por la vía más rápida: construir una entrevista muy distinta de la original. Nadie en la redacción y muy pocos lectores advirtieron en su momento el evidente fraude (Vila-Matas, "Lo que Brando decía", Dezine, 01/10/1980: 582²7.
\end{abstract}

Tras ello, en la introducción del texto, Gilmore (Vila-Matas) informa al lector de que acaba de sufrir un desengaño amoroso, está resfriada y su llegada al hotel en el que se "esconde" Brando ha supuesto una hazaña militar. Al igual que la cínica creatividad de las preguntas y las respuestas que integran la entrevista, el párrafo tiene un claro signo de relato de ficción:

Ir hasta el hotel Wayland, en Providence, donde Marlon Brando se hospedaba en el más riguroso incógnito, me resultaba tan difícil como planear una gran campaña militar. Llevaba varios días resfriada, tenía fuerte dolor de riñones que me impedía nadar con cierta normalidad, y para colmo había sufrido en la última semana el más fuerte desengaño amoroso de mi vida. Por si no fuera esto suficiente tuve que coger un tren de madrugada, lo cual supuso pasar toda la noche despierta. Subí la cuesta a la estación caminando muy encorvada, y comencé así mi periplo. Estaciones de St. Louis, Indianápolis, Columbus, Donora, Phoenixville, Philadelphia, New York. Llegué renqueando a Providence. Por Jefferson Street, una tranquila calle que rodea el barrio comercial, avance hasta una plaza con hayas y arces, Wayland Square. Allí estaba el hotel en que Brando se ocultaba de las miradas del mundo. ¿Me recibiría? Lo hizo, pero con evidente mal humor, y la entrevista fue tan tensa como breve. Le localicé en el bar. Brando estaba dibujando, con lápices de colores y especial dedicación, una isla. Sobre la mesa había, junto al estuche de Carandache, un libro de Kafka y 
una cajetilla de Camel. Pasó la mayor parte de la entrevista con la mirada hundida en esos objetos (Vila-Matas, "Lo que Brando decía", 1992: 114).

A partir de aquí y a lo largo de la entrevista Brando no dejará de traspapelarse con la personalidad vila-matiana, la cual se muestra: bien polifacética e impostada, afirmando kafkianamente que no puede soportar a su padre en el recuerdo, bien desinhibida para opinar que los hippies son "como los héroes del cine mudo" (ibidem) o bien autobiográfica, manifestando que siempre deseó una vida de acción y aventura para añadir que piensa: "[...] en las noches en el oasis y en la maravilla de vivir en el anonimato" (ibidem) o que "[...] todas las mañanas, sin excepción, me dedico a pasear por una isla, inventándola" (ibid., 115). He aquí, pues, no pocas claves del desarrollo bajo el que se moverán en adelante sus textos ensayísticos: desde la alargada sombra de Kafka o la cuestión del anonimato y la desaparición, hasta los viajes inventados. Podría hacerse un detallado y similar recorrido con el resto de sus entrevistas falsas ${ }^{28}$ y nos apercibiríamos, prácticamente en todos los casos, de lo que hemos observado con las dos entrevistas falsas a Brando: en un terrero de presunta entrevista a un personaje del mundo del arte o la cultura, despliega un precipitado de ficción articulador de parámetros embrionariamente ensayísticos y transpersonales.

Dentro de su trayectoria literaria, el punto cronológicamente intermedio del que queremos hacernos eco, como confirmación y avance del ensayismo que incorpora crítica y ficción, se deja ilustrar, por ejemplo, con el artículo: "Del lado del diablo sin saberlo" (La Vanguardia, 24/11/1987) ${ }^{29}$, el cual viene, para empezar, acompañado de una cabecera con un alto grado de dolo (la última parte del artículo se titula sintomáticamente "Engaño necesario") sin que apenas nadie, aparentemente, se diera por enterado de ello. Al margen de la multitud de datos falsos o ficticios que se destila en dicha cabecera, se anuncia al lector la idea de que la muerte y el mal son, de todos los lujos concebibles, los más costosos. Y que, por mucho que aquellos supongan negaciones extremas, numerosos autores han encontrado en ellos:

\footnotetext{
$28 \quad$ Entrevistas que aparecieron -además de una a Rudolf Nuréyev también en Fotogramas-en el diario La Vanguardia y en la revista Diagonal (en ocasiones, bajo distintas versiones entre ambos medios) para los casos de Patricia Highsmith, Anthony Burgess o Cornelius Castoriadis.

29 El cual lleva un título de sarcástica aproximación autobiográfica: es sabido que Jordi Llovet reveló a Vila-Matas que la primera letra de su nombre y sus dos apellidos daban, escritos o leídos al revés, "Satam alive". Dentro de la narrativa de Vila-Matas este hecho se divulga por primera vez en tanto que desdoble de información autoficcional a través de la voz narradora del relato "Me dicen que diga quién soy" (Suicidios ejemplares, 1991). La relación de Vila-Matas con lo satánico ha sido señalado por distintos autores (cfr., Zoe Alameda, en Andrés-Suárez y Casas, 2007: 55). 
"el fundamento de lo positivo de la creación literaria" ("Del lado del diablo sin saberlo", La Vanguardia, 24/11/1987: 52). A partir de aquí, y entregando una historia ensayística de ecos borgianos, el artículo va a desarrollarse desde una supuesta cita del secreto escritor Fritz Meier ${ }^{30}$ escrita en 1929 en referencia a Oscar Wilde, basada en la idea de que la mayor fascinación que producía la figura de Wilde se debía más a su vida que a su obra. Percepción en la que, dice Vila-Matas, cabría inscribir a Meier, porque también su vida tuvo, al parecer, más relieve que su obra; lo que sirve a Vila-Matas de apropiado justificante ante la probable circunstancia de que el lector se interese por la obra de Meier y descubra que no hay forma de dar con ningún dato al respecto. Tras ello encontramos un guiño intertextual a su propia obra, al añadir que Meier fue básicamente un escritor satanista que acompañó en sus andanzas a Alister Crowley. Por último, revela al lector que la breve y presunta obra de Meier tiene un especial punto de interés en el libro de memorias que este publicó con el título de Bamboleo. Una obra que a Vila-Matas le servirá para extenderse acerca de sus ideas sobre la creación literaria, en el seno de un artículo literario recalibrado en sus posibilidades creativas a medida que avanza la escritura ensayística del mismo, inventando toda suerte de anécdotas en torno a Meier. Con ello, no ha hecho sino trazar un texto en el que se están despachando informaciones culturales como verdades propias de un ensayo al uso cuando, en realidad, también se está abordando una historia de ficción. Así, por ejemplo, a través de un descubrimiento de infancia sucedido a Meier a partir de un teatro de marionetas ${ }^{32}$, leemos:

\footnotetext{
Y así llegamos a otro de sus recuerdos, el que da título al libro y el más estrechamente vinculado al descubrimiento de la ficción. Lo sitúa Meier en una radiante mañana de otoño en la que su familia le lleva a un parque de atracciones en las afueras de Sulingen y allí, en el intrincado laberinto de reclamos para la diversión infantil, descubre un teatro de marionetas ante el que se [sic] sentirá de inmediato una turbación descomunal. "Al término del espectáculo le juré a mi padre que las figurillas no lloraban ni reían de verdad." Descubrimiento, pues, del mundo de la ficción y, al mismo tiempo, descubrimiento (si se quiere algo banal) de que "al igual que los dioses juegan con nosotros, así jugamos nosotros también con las criaturas de nuestro Arte, poniendo en ello toda nuestra alma, desgraciada y ansiosa por recuperar en las figurillas la gracia perdida, esa gracia que ya solo la tiene un dios, o bien algo como la materia de una marioneta a la que el artista imprime
}

\footnotetext{
31 Fue, efectivamente - dentro de la trayectoria literaria de Vila-Matas-, en el parteaguas de ficción ensayístico-narrativa que resultó ser Historia abreviada de la literatura portátil (1985) donde supimos por primera vez de la relación entre Meier y Crowley en tanto que sujetos adscritos a la caravana de los shandys.

32 Vila-Matas volverá a hacerse eco de una historia infantil que relacione literatura y teatro de marionetas a través de una anécdota ocurrida a Sánchez Ferlosio con su hija Marta de 3 años, caminando ambos por el madrileño parque de El Retiro durante el verano de 1959 (cfr., Vila-Matas, "Dueños de nuestro propio ahora", Letras libres, abril 2004). Sánchez Ferlosio abrió la lectura de su discurso para la entrega del Premio Cervantes 2004 precisamente con este recuerdo.
} 
el sencillo movimiento de balanceo o bamboleo de la muletilla de mando". Tras el descubrimiento ensayará el bamboleo ante sus compañeros de juego y descubrirá que templa bien la muletilla y que divierte cuando inventa pasiones desquiciadas y que su capacidad de hacer el Mal es infinita, pues puede disponer de sus criaturas como le plazca y ser de una malignidad extrema con los espectadores. "Me parece que descubrí, aquel día, la libertad misma. Acababa de asomarse al mundo de la ficción (o tal vez era que el mundo me parecía ya una ficción), y ya me sentía yo a un solo paso de la literatura y, en consecuencia, del goce extremo y peligroso de cierta libertad que hasta entonces me había sido ocultada." (Vila-Matas, "Del lado del diablo sin saberlo", La Vanguardia, 24/11/1987: 52).

Como vemos, los remolinos y saltos en torno a la crítica y la invención literarias toman un expedito protagonismo en este artículo ensayístico. En esta forma de escribir, pues, que se venía anunciando con relativo sigilo desde el comienzo de la trayectoria periodística y literaria del autor - que explosiona, desacomplejada e inspirada, a partir de sus artículos literarios de los años ochenta - reencuentra y confirma Vila-Matas la piedra de toque de su estilo literario y de las búsquedas intelectivas y creativas que hemos visto desarrollarse exponencialmente en su obra, desde finales del siglo XX en adelante. En efecto, desde el último cambio de siglo, su obra, tanto la narrativa como la ensayística, se ha resuelto en una fusión de elementos, cuyo voltaje y premeditación vino avalada por precedentes como las entrevistas falsas, las críticas de cine de sesgo ensayístico y los artículos literarios en los que ficción y ensayo comparecían con intercambiable autoridad o jerarquía. No en vano, ha sido en los últimos 15 años cuando sus ensayos han perfeccionado sus desvíos ficcionales y su narrativa; en las ocasiones que así se lo ha propuesto, ha planteado sin ambages sus pretensiones más complejas. Es cierto que su novela actual no se ve incesantemente interpolada por la densa licitación ensayística que encontramos en El mal de Montano (2002) o Doctor Pasavento (2005); pareciendo incluso patente que su relato y su novela han convergido en la última década hacia un mayor aperturismo lector y una serie de tramas menos irresolubles o, cuanto menos, haciéndose fuertes desde una ubicación emocional que viene a recuperar cierta narratividad perdida. Pero, temáticas como los vericuetos de la creación literaria, el momento artístico del mundo o las consecuencias culturales de la modernidad continúan, sin duda, siendo un insoslayable centro de atención y reflexión en sus novelas. 
El articulismo y el ensayismo del autor ha seguido, sin embargo, una línea más regular. Ya en el tránsito del siglo XX al XXI encontramos, por ejemplo, dos nuevos y mayores paradigmas de su bagaje de crítica inventiva, dos ensayos concebidos como una dupla de planteamientos literarios libérrimamente autoexplicativos e introspectivos, a la vez que narrativos y parcialmente ficcionales. Nos estamos refiriendo a "Mastroianni-sur-Mer" $y$ "Un tapiz que se dispara en muchas direcciones", los cuales no solo han sido incluidos en repetidas ocasiones en sus recopilaciones de artículos y ensayos ${ }^{33}$, sino que, de alguna forma, nacieron hermanados por un similar perfil de encargo -destinados, de hecho, a ser una conferencia ${ }^{34}$.

Si "Mastroianni-sur-Mer" es un ensayo narrativo a modo de reacción en cadena, aglutinante de sus propias capas de autoconstrucción a medida que profundiza en sí mismo y para el que eligió discurrir sobre las relaciones entre la película Sostiene Pereira (Roberto Faenza, 1996) y la novela de Tabucchi de la que esta procedía (publicada por Feltrinelli en 1994). Para "Un tapiz que se dispara en muchas direcciones", se decidió por leer, para la citada emisión radiofónica, el final del relato "Los muertos" de Joyce (Dublineses, 1914); elección facilitada por estar aún bajo la reciente impresión de haber visto esta obra del autor irlandés indirectamente referenciada en Viaggio in Italia (1953) de Rosellini, a través de una evocación de Ingrid Bergman y George Sanders. Estas coordenadas de arranque discursivo posibilitarán dos ensayos en los que cabe la incursión de la ficción, sin menoscabo de un amplio desarrollo crítico-ensayístico, en torno a las fronteras y los mestizajes operados entre literatura y cine; haciendo ensayo al andar de la mano de la conocida cocina de Vila-Matas a través de autores como Rosellini, Walser, Joyce, Pitol, Magris, Sebald o Borges, entre otros; los cuales no dejan de mezclarse con la propia obra de Vila-Matas, vista desde su taller de producción y autocomprensión o con temáticas como el compromiso ideológico en la literatura, la incomunicabilidad, etc. Ocurre así que en estos ensayos-conferencias se solaza como crítico literario de sí mismo, inventa fragmentos

\footnotetext{
Entre otros lugares, ambos ensayos aparecen, por ejemplo, tanto en Desde la ciudad nerviosa (2000) como en El viento ligero en Parma (2004) y Una vida absolutamente maravillosa. Ensayos selectos (2011).

34 "Mastroianni-sur-Mer" debía ser una conferencia dictada el 28 de enero de 1999 en el Palau Macaya de Barcelona sobre las relaciones entre literatura y cine y "Un tapiz que se dispara en muchas direcciones" respondía, en principio, a una doble solicitud que se le habría hecho a Vila-Matas hacia el cambio de siglo: por una parte, una invitación de un programa radiofónico para que el autor leyese un fragmento literario en antena con el fin de que los oyentes averiguasen de qué obra se trataba y, por otra parte, una conferencia que versara sobre el mestizaje y los géneros en la novela del futuro a propósito de la entonces reciente aparición de Bartleby y compañía (2000).

35 Lo comprobamos dentro de "Un tapiz que se dispara en muchas direcciones", por ejemplo, a través de la entrada "La ficción es sólo una parte de la trama", donde mantiene su autor una reflexión que encontraremos plasmada en las que entonces serían sus novelas por venir El mal de Montano (2002) y Doctor Pasavento (2005): "[...] la anécdota inicial, que al desarrollarse se convierte en trama, es sólo una parte de la trama global: una parte que no ocupa excesivo espacio; la parte ficcional es más bien mínima y convive, entre otras, con la ensayística y la documental. Y tiene una característica que aún la hace más mínima, no se desarrolla demasiado, casi recuerda a esa prosa de los relatos de Robert Walser [...] prolongada cháchara que esconde la ausencia de cualquier progreso" (Vila-Matas, 2008: 75).
} 
autobiográficos o experimenta con los modos literarios de armazón híbrida que mayor seducción y esperanza le producen; los cuales, además, sirven para fijar ideas de estructura formal y encontrar caminos temático-reflexivos para sus futuras ficciones ${ }^{35}$.

Otras piezas todavía paradigmáticas de su ensayismo de los últimos lustros son textos misceláneos como: "Solo o en compañía de críticos" (2003) o "Chet Baker piensa en su arte" (2011). En el primero de ellos expone, en tanto que narrador autodiegético, el desarrollo de un leve y desenfadado hilo narrativo, a partir de un encuentro mantenido con Jordi Llovet en el restaurante Ponsa de Barcelona. El objetivo de la reunión tiene que ver, en teoría, con el hecho de que Llovet le oriente sobre un escrito que relacionará creadores y crítica, teniendo en cuenta que tanto crítica como autocrítica de traslación ensayística son las formas que, de modo más común, Vila-Matas entiende por creación. Con ello, irá presentando el despiece mental -podríamos decir casi en directo o en tiempo real- de un texto que va encadenando, con sus propios movimientos ensayísticos, crítica y autocrítica dentro de un bucle de creación literaria.

No solo es un hecho que crítica, autocrítica y creación se han ido manifestando insufladas entre sí cada vez más vivamente en su escritura a lo largo de su trayectoria literaria, sino que el hecho de que el autor se ocupe de un texto desde tal perspectiva -deslizando en el mismo, como también suele ser habitual en él, no pocos elementos de autobiografía, ironía y humor-, a través de un artículo que parece un cuento o viceversa y de una extensión considerable (en la que logran concentrarse distintas fuerzas formales de intervención textual, sin que se disgregue finalmente la consecución de un resultado compacto). Esto otorga al autor los recursos y vericuetos óptimos por los que avanzar o desviarse a su conveniencia resultándole, al cabo, la fórmula empleada no solo teoréticamente lábil sino ficcionalmente productiva ${ }^{36}$, desde su libérrima posición de creador, llevado por la expansión crítica. Afirma haber estado forzando así: "[...] aún más mi posición crítica y la sensación de lucha en el novelista-crítico en el que me estaba convirtiendo [...] y yo ahora soy un crítico que escribe novelas y sugiere -o busca- nuevas formas para la novela"137.

El otro ensayo al que nos hemos referido y con el que cerraremos este trabajo, "Chet Baker piensa en su $\operatorname{arte}^{\prime \prime 38}$, obedece muy probablemente (junto a otros textos que podrían estar

\footnotetext{
36 Véase al respecto, por ejemplo, la invocación de Alberto Manguel hacia el final del texto como una supuesta presencia real que no es improbable que haya sido inventada por Vila-Matas como simple recurso narrativo.

37 Vila-Matas, "Solo o en compañía de críticos", en Ródenas de Moya, 2003: 127.
} ensayísticos publicados previamente en prensa: "Doctor Finnegans y Monsieur Hire" (El País, 10/10/2009) y "Chet Baker piensa en su arte" (El País, 31/01/2010). 
representados por un ensayo tan conseguido como Perder teorías (2010), por ejemplo) al tipo de escrito ensayístico más airosamente afectado de su estilo tardío o, lo que es lo mismo, uno de los más ambiciosos y logrados de cuantos le hemos conocido al autor barcelonés. Por cuanto, siendo ensayos e introduciendo al lector en un venturoso y por momentos majestuoso juego de espejos especulativos y meandros metaliterarios, registran igualmente una incorporación de tejido narrativo altamente inflamable — por la pérdida de "seguimiento" a la que podría terminar cediendo la persona que lee el texto. De todo lo cual, sin embargo, su autor sale no solo indemne, sino distinguido, si tenemos en cuenta el balance de lo que propuso y lo que consiguió.

Hilándose en su comienzo con el tema musical "Bela Lugosi's Dead" en la versión de Nouvelle Vague y la frase orteguiana perteneciente a Meditaciones del Quijote sobre la naturaleza "bárbara, brutal, muda sin significado, de las cosas", el relato de ficción crítica -tal es su subtítulo- "Chet Baker piensa en su arte" viene desarrollado por el hecho de que Sergio Chejfec se hubiera debatido poco tiempo antes entre las estrategias novelísticas presumiblemente antagónicas de Joyce y de Simenon -entre la narración como arte y como discurso, entre el mundo interior y el exterior- en su novela Mis dos mundos (2008); terminando el autor argentino por mostrarse cómplice y concertador de ambas tendencias. Compuesta de cuarenta entradas o secciones, "Chet Baker piensa en su arte" termina siendo una nouvelle crítica que, pretendiendo hacer creer al lector que está escrita con ánimo de que no sea leída por nadie que no sea el propio narrador (el cual es crítico literario, pues compagina su trabajo tanto con su puesto en una biblioteca municipal como con la traducción de novelas francesas y tiene mujer e hijos) va a ser leída por sus lectores como un ensayo que fue presentado como relato dispuesto a criticar.

La idea central del artificio -ensaya aquí Vila-Matas- obedecería a la siguiente premisa: cuando no existe o no se da la simplicidad narrativa, se aprecia y reflota con mayor denuedo la realidad que no puede sino mostrarse bárbara y chata en sus circunstancias expresivas. El no narrar sería más afín a la vida bárbara y aquel que no narra, añade Vila-Matas, percibe la vida bárbara en la propia naturaleza ruda de cuanto existe. Además del legendario aura de Chet Baker, la obra de Musil o el simbólico paralelismo oficiado a través de Voyage autour de ma chambre (1794) de Xavier de Maistre, todo ello lo ilustra procelosamente Vila-Matas a partir de los arbotantes ideológico-literarios a los que ya nos hemos referido con Joyce. Y, como contrapunto de una obra 
propiamente narrativa, Simenon, que funcionará dentro del relato como el leitmotiv sobre el que enfrentar el cultivo de la reflexión literaria, azuzado de dudas y probaturas.

No parece sino que con este tipo de "ficción crítica" hubiera buscado siempre llegar donde ha llegado hoy, describiendo con ello una trayectoria de escritor que solo sabe descansar casi en la innovación del ensayo. O lo que es lo mismo, Vila-Matas ha pretendido acorralar una ficción con la que ensayar más allá del ensayo. Se trata de una visión del ensayo, en fin, aireada desde sus cimientos por el soporte sinérgico de una ficción en estado de descaro. La contemporánea y bárbara realidad orteguiana es percibida, en especial — dice Vila-Matas— por todos aquellos que, al modo de Musil, ya no creen que exista en el mundo la simplicidad inherente al orden narrativo. Musil es aquí, desde luego, un frecuentador de realidades fragmentarias sin acceso posible al orden unidimensional, aferrado a la creencia postuladora de la desaparición de la narración. A partir de esta introducción general, Vila-Matas establece la aparente distopía de anunciar el parejo placer artístico que le procura la no narratividad joyceana de Finnegans Wake (1939) y el ingenio narrativo de Les fiançailles de Monsieur Hire (1933) de Simenon. Tras la apuesta de la obra de Joyce por relacionarse con la escritura que trate de sancionar la verdad de la vida incomprensible, Beckett viene a opinar -añade Vila-Matas- que el arte realista engendra obras discursivas porque se centra en hablar de las cosas, mientras que el arte auténtico discurriría con mayor propiedad siendo las cosas en sí mismas y no algo sobre las cosas. Dicha visión beckettiana no lleva a suponer, empero, que mientras hablamos de algo comenzamos insalvablemente a alejarnos de ello, ya que solo dependiendo del acierto de cómo hablemos nos alejaremos más o menos del objeto que anima nuestro discurso. Y, sin embargo, Simenon sabe poner en marcha -concluye Vila-Matas- un entramado de enigmática narración, insuflada por la simplicidad del orden que hemos perdido en la actual realidad.

He aquí el trazo grueso de la reflexión despachada por lo que entendemos como el grado último, inclusivo y superlativo, de su ensayismo. Un ensayo que no ha hecho sino diseñar un dilatado y sugestivo camino de introspección y experimentación literarias, desde aquellos primeros artículos de crítica cinematográfica y entrevistas inventadas —acaecidos desde finales de los años sesenta-, hasta alcanzar los mejores artefactos de "ficción crítica" que han tenido lugar en la última y presente etapa creativa del autor. 


\section{Bibliografía}

CASAS, Ana y ANDRÉS-SUÁREZ, Irene (eds.), Enrique Vila-Matas (Grand Séminaire de Neuchâtel, Coloquio Internacional Enrique Vila-Matas, 2-3 de diciembre de 2002), Madrid, Arco Libros, 2007.

BLANCHOT, Maurice, L'entretien infini, Paris, Gallimard, 1969.

GRACIA, Jordi, "Todo mentira", El País, 27/11/2015.

DRAPER, Hal, Karl Marx's Theory of Revolution (Volume II, The Politics of Social Classes), New York and London, Monthly Review Press, 1978.

MAQUIAVELO, Niccolò, Lettere, Torino, Editrice Torinese, 2013.

PIGLIA, Ricardo, "Extranjeros del Cono Sur", El País, 03/03/2001.

POZUELO YVANCOS, José María, Figuraciones de yo en la narrativa: Javier Marías y E. VilaMatas, Valladolid, Universidad de Valladolid, 2010.

RÓDENAS de MOYA, Domingo (ed.), La crítica literaria en prensa, Madrid, Marenostrum, 2003.

----------, y GRACIA, Jordi, El ensayo español. Siglo XX, Barcelona, Crítica, 2008.

----------, y GRACIA, Jordi (eds.), Ondulaciones: el ensayo literario en la España del siglo XX, Madrid Iberoamericana, Frankfurt am Main, Vervuert, 2015.

SAID, Edward, On Late Style, New York, Pantheon Books, 2006.

VILA-MATAS, Enrique, "¿Adónde va el cine mesetario?", Fotogramas, 14/02/1969.

"Al servicio de su majestad James Bond", Fotogramas, 16/05/1969.

"Almería, cine independiente A-Z, de Fausto Romero", Fotogramas, 19/12/1969.

, "Azcona, el guionista número 1 del cine español", Fotogramas, 13/09/1968.

, "Bertolucci, después de la revolución", Fotogramas, 16/01/1970.

---------, "Cannes 77: Bajo el signo de los Taviani", Destino, 02/06/1977.

--------, "Carlos Estrada: 'No me gusto nada'", Fotogramas, 13/12/1968.

--------, "Chet Baker piensa en su arte", El País, 31/01/2010.

----------, Chet Baker piensa en su arte. Relatos selectos, Barcelona, DeBolsillo, 2011.

---------, "Clint Eastwood o el mito de un rostro impasible", Fotogramas, 23/08/1968.

----------, "Cuatro flashes sobre Fotogramas", Fotogramas \& DVD, número extra 2, 2006.

---------, "Del lado del diablo sin saberlo", La Vanguardia, 24/11/1987 (texto reeditado en El viajero más lento, 1992). 
----------, “Doctor Finnegans y Monsieur Hire", El País, 10/10/2009.

---------, “Dos realizadores holandeses: Pim de la Parra y Wim Verstappen", Fotogramas, 12/12/1969.

----------, "El cine a la hora sueca", Fotogramas, 29/11/1968.

--------, "'El cine lo es todo para mí, no sé hacer otra cosa'” [entrevista a Sonia Bruno], Fotogramas, 11/10/1968.

---------, "El director que dijo No a Sara Montiel" [entrevista a Jorge Grau], Fotogramas, $27 / 09 / 1968$.

----------, "El operador-jefe", Fotogramas, 30/01/1970.

----------, “Elena María Tejeiro, una 'gata' en el cine español", Fotogramas, 21/02/1969.

---------, El viajero más lento, Barcelona, Anagrama, 1992.

---------, El viento ligero en Parma, Madrid, Sexto Piso, 2008.

---------, “¿Ha muerto la Escuela de Barcelona?, Fotogramas, 07/02/1969.

----------, Hijos sin hijos, Barcelona, Anagrama (Compactos, CM 226), 2001.

----------, http://www.enriquevilamatas.com/escritores/escrwillwilkinson2.html.

---------, “Jaime Camino: 'Prefiero ganar un premio en Venecia o Cannes que aspirar al Oscar'”, Fotogramas, 24/01/1969.

----------, “La larga agonía de los actores fuera del agua", Fotogramas, 01/08/1969.

----------, "La verdadera historia del guionista Azcona", Bocaccio73, julio de 1973.

----------, "Ma nuit chez Maud, diálogos católico-marxistas en un salón burgués", Fotogramas, 07/11/1969.

----------, “Lo que Brando decía”, Dezine, 01/10/1980 (texto reeditado en El viajero más lento, 1992).

----------, "Marisa Paredes: 'Soy actriz por llevarle la contraria a la vida'”, Fotogramas, 11/04/1969.

----------, "Marlon Brando: 'Sé que puedo terminar asesinado como los Kennedy o Luther King'”, Fotogramas, 05/07/1968.

--------, "No hacía falta morir por esto' o el 'boom' del cine canadiense", Fotogramas, $17 / 01 / 1969$.

---------, "París ¿adónde fue tu revolución?", Fotogramas, 17/01/1969.

---------, “Raimon: 'Siento que me van eliminando'”, Fotogramas, 08/08/1969. 
, "Roland Klick o la nueva Alemania", Fotogramas, 10/01/1969.

, "San Sebastián 70. Una película de 10 días con muchas 'vedettes'", Fotogramas, 24/07/1970.

-, "Solo se debuta una vez", Fotogramas, 15/11/1986.

---, "Una evocación de la Escuela de Barcelona", La Vanguardia, 26/02/1999.

---------, "Un tapiz que se dispara en muchas direcciones", El viento ligero en Parma, Madrid, Sexto Piso, 2008.

---------, "Yugoslavia: visión de un cine joven", Fotogramas, 13/09/1968. 